\title{
THE COVID-19 PANDEMIC HAS EXPOSED OPPORTUNITIES TO STRENGTHEN OUR HEALTH RESEARCH SYSTEMS
}

VOL 44 NO 1 MARCH 2021 \author{
Aubie Angel, CM, MD, MSc, FRCPC, FCAHS ${ }^{4}$

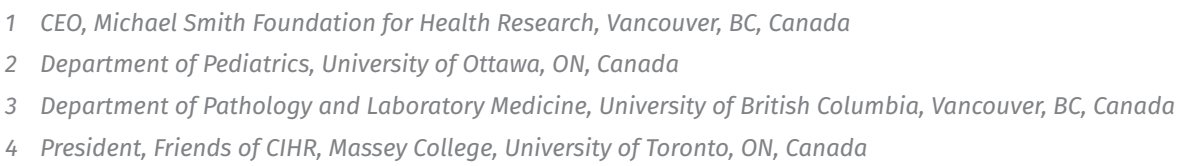

Bev J. Holmes, MA, PhD'1, Alex MacKenzie, MD, PhD², Bruce McManus, CM, OBC, MD, PhD, FRSC, FCAHS ,

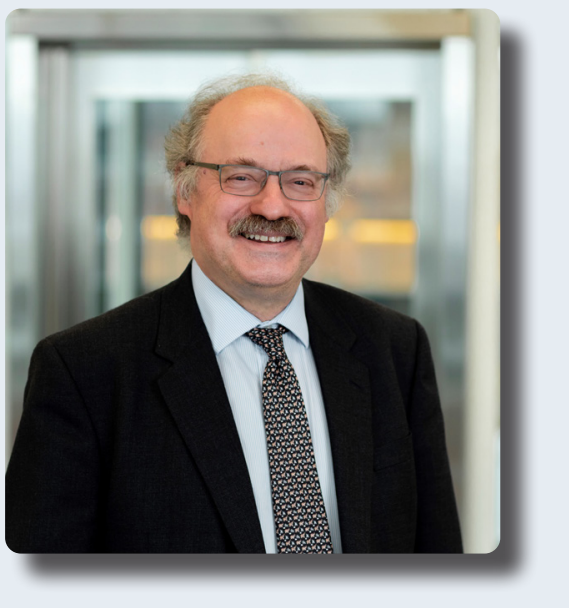

\section{INTRODUCTION}

The 2020 Henry G. Friesen International Prize in Health Research program was launched, like the majority of events last year, virtually. With coronavirus disease 2019 (COVID-19) casting a shadow on much of life today, the awarding of the Prize embodying excellence in health research resonated on both sides of the Atlantic Ocean. Our virtual separation underscored the central challenges of the pandemic but brought great hope as well.

The Friesen Prize, ordinarily presented in person in Ottawa at an event organized and hosted by the Friends of the Canadian Institutes of Health Research, took on a revised trans-national format due to COVID-19. In collaboration with the High Commission of Canada in London, UK, a distinguished panel of Canadian and the United Kingdom (UK) health research leaders listened to a keynote address by Sir Mark Walport, the 2020 Friesen Laureate. On October 2, 2020 at Canada House, under the auspices of Her Excellency Janice Charette (Canadian High Commissioner) and broadcast as a webinar out of Massey College, University of Toronto, Sir Mark Walport gave his view of health research priorities in the COVID-19 era. The framing of the nexus between research and health set the tone for the session. The panel, which included past Friesen Prize recipients, university presidents and leaders of funding agencies, congratulated Sir Mark Walport and provided their perspectives, which spanned two nations and which demonstrated a history of productive collaborations.

Their overall assessment? While the world has benefitted from a golden age of health research in our cross-sectoral, multi-disciplinary response to the severe acute respiratory syndrome coronavirus 2 (SARS-CoV-2), the pandemic has thrown a host of societal challenges, both local and global, into sharp relief. Health and educational inequalities, population hyper-densities, economic frailties, systemic racism, persistent poverty and global warming have all been exposed as weaknesses in societies that increase the likelihood and severity of any global pathogen outbreaks. Addressing 
these issues requires fresh minds, urgent attention and sustained purpose. Among these opportunities, a few rise to the top.

\section{Culture of the research enterprise}

The pandemic has emphasized the importance of research, not only in highly specialized areas, but across many disciplines beyond medicine and health, including the social sciences, the arts and engineering. Resolution of complex health issues demands insights not only from basic and molecular science, clinical study, health services and public health research, but as also from study of social determinants, given the impact of COVID-19 on daily life. Although researchers are willing to collaborate across these disciplines, the system primarily rewards them for working in isolation and competing with each other for funds and recognition. Further, an exploration of the tensions between research investments in areas directly related to health and those that affect health in less obvious but socially significant ways (housing, income, employment, education) is clearly needed, as is attention to unhealthy competition, systemic racism and persistent sexism in the research enterprise itself. More diversity in research leadership would help bring about much-needed approaches.

\section{Top down and bottom up priorities}

History has demonstrated the critical importance of discovery or "curiosity" research. Yet, science must also tackle the often larger questions of direct pertinence to policy makers and to society more broadly. It must be possible to balance a free market of ideas and the attendant sometimes lengthy time needed for their realization, with a societal responsibility to respond to urgent issues of the day. With the world confronting related crises, such as climate change and the current pandemic, the results of science in decision-making have never been more important, nor has the need for science to heed the needs and aspirations of citizens. Standing structures are needed to support discussion and action among academia, government, industry and civil society, to further the synergy between capabilities that reach from the bottom up in creativity and originality and from the top down when arising from pressing societal issues that demand solutions sooner.

The next generation

Young scientists need to be supported for their creativity, energy and insight, allowing them the free rein needed to make important breakthroughs. There is strong and increasing evidence that the pandemic, superimposed on a system already too focused on individual competition, is further endangering the careers of young and mid-career investigators-as well as their perception of the viability of science as a profession. Co- ordinated action by governments, funders and research leaders is needed. Solutions must include attention to the recruitment of capable people from underrepresented segments of society into the research enterprise. New definitions of success beyond high impact publications may help bigger, better thinking and inquiry.

\section{Science in society; with society; for society}

Given the profusion of counter-productive and incorrect information circulating in the public sphere as witnessed during the pandemic, the need for clear scientific communication has never been greater. Communication should not be unidimensional; it must not be among scientists of one discipline alone but also between those of different disciplines, as well as between scientists and the public and other stakeholder groups, such as government and the media. The current experience with the confused messaging about the availability and deployment of precious vaccines is a case in point. We suggest that 2021 should be a year for significant efforts related to scientific engagement, transparency and openness.

Learning from COVID-19 to strengthen science as a public good

The foundations of the global research system are being challenged, but the valuable lesson in COVID-19 is that science, including the research that will halt the pandemic, can be better supported, coordinated and informed for greater societal benefits. Canada and the UK are well positioned to partner to realize these benefits for ourselves and others. Our universities, research institutes and funders can both look within to resolve some acknowledged-and now heightened-research system issues, and reach out to governments, civil society and industry to better co-develop sustainable and effective solutions to the world's most pressing health problems.

\section{SIR MARK WALPORT ON THE CANADA-UK OPPORTUNITY FOR HEALTH RESEARCH}

The following are quotes from Sir Mark Walport's Friesen Prize inaugural keynote presentation and panel discussion (https://youtu.be/u2ZrJADFMAA).

"We collectively have a deep belief in the power of research for the improvement of health and in the prevention and treatment of disease. And indeed, more broadly for the health of our planet and for the other species with which we share it."

"What comes out consistently is the importance of future generations, for whom we need to provide sustained support such that they can really tackle interesting and difficult problems."

"We share important values among us, as scientists, but also as nations. There is an enormous opportunity to work together and we must not miss it." 